REVISTA DE SOCIOLOGÍA

$\mathrm{N}^{\mathrm{o}} 17-2003$

Facultad de Ciencias Sociales - Universidad de Chile

(P. 95-123)

\title{
La Tecnocracia: el falso profeta de la Modernidad ${ }^{85}$
}

\author{
Alberto Mayol Miranda* \\ Por ese medio sólo conseguirán impedir que se tome plena conciencia \\ de la verdad fundamental: de que el profeta por el que una parte \\ de nuestra generación suspira no existe... Nos ha tocado vivir en \\ un tiempo que carece de profetas y está de espaldas a Dios"
}

\section{Max Weber}

\section{Sumario}

El carácter nuclear del problema de la racionalidad para comprender el fenómeno de la tecnocracia bien puede estar en el eje de este intento por dar una entrada teórica a un asunto que suele relegarse al estudio de caso. La racionalidad, como aspecto constitutivo e inspirador del proyecto moderno y como un problema esencial del mismo, es indispensable en el estudio de cualquier pretensión por vincular la razón con alguna 'verdad' políticamente relevante. La restricción y amputación de la multidireccional razón y su cristalización en un proyecto unívoco, inmunizado mediante un tabú de la crítica, basado en una aséptica racionalidad técnica, supone la negación del carácter histórico de la razón, que no sólo es una premisa sociológicamente inadmisible (¿se puede sociológicamente negar la historicidad de lo social?), sino además un potencial de destrucción de la esfera de la politicidad. Por esto, merece atención la argucia de que la Modernidad sería la búsqueda de la razón definitiva y que la tecnificación de las decisiones sería su punto final, argucia que no es otra cosa que la falsa profecía de una Modernidad que en rigor tiene poco de moderna. En este discurso tecnocrático (pero no sólo discurso) está la promesa de una política unívoca, definitiva, incuestionable y operacionalizable, la promesa de que el sentido de la historia encuentra en la razón técnica la orientación fundamental. Sin embargo, la tecnocracia no parece ser sino lo contrario a una orientación fundamental, siendo otra forma más de la pérdida del sentido y de la libertad que Weber detectaba como una jaula de hierro hacia donde iba la racionalidad en el capitalismo. Es así como la

\footnotetext{
${ }^{85}$ Este artículo es en parte una síntesis, pero también una revisión y reversión de una homónima tesis de magíster del autor. Véase MAYOL, Alberto (2002); La Tecnocracia; el falso profeta de la Modernidad. Una crítica a las propuestas tecnocráticas desde la teoría política. Tesis para optar al grado de magíster en ciencia política de la Universidad de Chile.

"Sociólogo y magíster en ciencia política, Universidad de Chile. Licenciado en estética, Universidad Católica de Chile.
} 
tecnocratización sólo puede desenvolverse en tanto anulación de la posibilidad de que sean los hombres los que construyan su historia.

\section{Introducción}

Que la razón sea histórica, contingente, heterónoma, es quizás una observación banal. Cualquier sociólogo ha de estar convencido de que el reino de la necesidad se construye en la contingencia. De lo contrario, a qué hacer sociología. Nietzsche fue tan lejos (vaya novedad) que vio en el origen de la razón la lucha, el espíritu agonal. La sospecha de que detrás del universal estaba la voluntad de poder fue una luz histórica (paradojalmente construida sin antecedentes históricos) que dio de lleno en la secular religión hegeliana del desarrollo del espíritu absoluto. Y nada de raro, pues la Modernidad tuvo (tiene, tendrá) tanto de salvífica. Y, por eso, de ingenua, si me permiten.

Por esto de la contingencia es que no es raro que cada época tenga su razón. Y no es nada de extraño que sus avatares afecten (y sean afectados por) las cuestiones del poder. Por eso este escrito no tiene novedades. Ya muchos saben que la tecnocracia representa algo así como la razón del capitalismo en su estado actual. Es la razón de la operación, de la curva de oferta y demanda, de la economía comercial, de la transacción, del individualismo construido desde el actor del intercambio. Por demás, ya lo había dicho con sublime asertividad Weber, aunque de manera demasiado bella como para (yo) haberlo notado antes.

"El cuidado por los bienes exteriores, decía Baxter, no debía ser más que un liviano manto que se puede arrojar en cualquier instante sobre los hombros de sus santos. El destino ha convertido este manto ligero en 'una jaula de hierro" ${ }^{86}$. La ascesis emprendió la tarea de actuar sobre el mundo y transformarlo; con ello, los bienes exteriores de este mundo alcanzaron un poder creciente y al cabo irresistible sobre los hombres, un poder que no ha tenido semejante en la historia. Hoy su espíritu se ha deslizado fuera de esta 'jaula', quién sabe si definitivamente. El capitalismo victorioso, descansando como descansa en un fundamento mecánico, ya no necesita en todo caso, de su sostén. También parece definitivamente muerto el rosado talante de su optimista heredera, la Ilustración (...). Nadie sabe todavía quién habitará en el futuro esta 'jaula' vacía, nadie sabe si al cabo de este prodigioso desarrollo surgirán nuevos profetas o renacerán con fuerza antiguos ideales y creencias, o si, más bien no se perpetuará la petrificación mecanizada, orlada de una especie de agarrotada petulancia. En este caso los 'últimos hombres' de esta cultura harán verdad aquella frase: "especialistas sin espíritu, hedonistas sin corazón..." (Weber, 1998a: 199, 200).

La observación de Weber tiene más de arrebato místico que de análisis. Es el instante en que Weber percibe que todo calza y que un misterioso sentido deambula en su desencantado mundo (es quizás el sentido de la pérdida del sentido). Pero, después de todo,

\footnotetext{
${ }^{86}$ Esta es la clásica cita de Weber sobre la 'jaula de hierro', es decir, sobre la doble pérdida de lo sustantivo y de la libertad que van mostrando los procesos de racionalización. La traducción aquí utilizada usa 'férrea envoltura' en lugar de la clásica 'jaula de hierro', pero me he permitido devolver el clásico término, vulnerando así la traducción, pero respetando la forma en que es comprendido este párrafo por los sociólogos.
} 
una buena teoría es consistente, clara, recursiva y, por consiguiente, algo paranoica. Y es así siempre que esa teoría tiene un momento de encuentro de la parte con el todo, es decir, siempre que está acabada. Por esto es que toda buena teoría, en su punto de encuentros múltiples, tiene (puede tener) algo de arrebato místico. Ahora bien, la cita a Weber bien puede ser el eje de todo este artículo y de hecho ya lo rebasa. Puede ser ella la matriz de toda una investigación bastante más extensa. Quizás no haya aquí más que un comentario de esta cita, un intento por hacer una exégesis, una mera adaptación ante el libro sagrado. Se asume el teologal riesgo. Si se quiere en estilo borgiano, salvo el plagio, todas las demás formas de repetición son la base del conocimiento. Lo concreto es que aquí se quiere decir, simplemente, que sí se ha perpetuado la mecanizada petrificación de la razón, que sí está representada por nuevos profetas, que sí son petulantes (esto es lo más verificable de todo). Se quiere decir que sí estamos ante esos 'últimos hombres', que en sentido ingenuamente positivo llamó de igual modo Fukuyama, que sí son visibles esos especialistas sin espíritu. Más aún, se pretende decir que son precisamente ellos los nuevos profetas, recursivos seres que prometen lo que ya es, la razón mecánica y petrificada, que luego tiñen con el rosado talante de la bella Ilustración, con la promesa de la Modernidad, esa promesa de sentido convertida en mero engranaje lleno de desencanto. Son los profetas que prometen el arribo de una Ilustración ya muerta. Sólo se quiere decir, entonces, que la tecnocracia es la forma que ha adoptado esa esperanza y que a la vez se torna la operatoria misma de la razón petrificada. Y que ella misma es profeta que anuncia su propia llegada.

¿Se está diciendo que Weber tenía previsto el fenómeno de la tecnocracia? Ni el 'no' ni el 'sí' son respuestas razonables (para el caso). Por supuesto, la detección de lo que se suele llamar el problema de la 'jaula de hierro' no aparece directamente vinculado al análisis de la tecnocracia. Pero (y esto es parte de lo que se quiere decir), la tecnocratización no es un proceso que se diferencie y distinga claramente de las caracterizaciones weberianas sobre la racionalidad. Para Weber, por cierto, el fenómeno que le parecía familiar era la burocracia. Pero en lo general, lo que vio fue una dinámica característica de la forma en que se 'desenvuelve' la racionalidad y, específicamente, la racionalidad en el capitalismo. A partir de esta tendencia consideraba, por ejemplo, que la burocracia era el camino unívoco de la modernización del Estado. Y detectó a la burocratización como una forma fundamental de los procesos de racionalización organizacional. Pero no es menos cierto que Weber veía en la empresa privada un grado de racionalidad instrumental más agudo que la que estaba operando en las esferas burocráticas. La burocracia podía ser la forma más racional de organización, pero Weber cree ver un mayor

"conocimiento de la especialidad de los hechos dentro del círculo de sus intereses (... en) el interesado privado de una actividad lucrativa. Es decir, el empresario capitalista. Es realmente la única instancia inmune (o al menos relativamente) frente a la ineludibilidad de la dominación científico-racional de la burocracia. Todos los demás, en las asociaciones de masas, están irremisiblemente sometidos al imperio burocrático" (Weber, 1996: 179).

Por supuesto que Weber no tematizó la posibilidad de que estas dinámicas en la empresa capitalista podían pasar a la política, particularmente al Estado. Pero si nos concentramos en el problema de la racionalidad en su conjunto, parece ser viable vincular a las dinámicas generales de la racionalización en el capitalismo (la creciente instrumentalización, por ejemplo) con los procesos de las organizaciones racionales ejes, como la empresa 
capitalista y el Estado moderno. Lo concreto es que fue Horkheimer el que dejó muy claro que el proceso de traslado del especialista propio de la empresa capitalista a la política -y particularmente hacia el Estado- era viable y que históricamente estaba ocurriendo.

"Con el rápido proceso de concentración y centralización del capital que, mediado por el despliegue de la técnica, ha tenido lugar en el último siglo, los propietarios jurídicos han sido apartados en buena medida de la dirección de las gigantescas empresas que se van formando y que absorben sus fábricas, con lo que la dirección se autonomiza frente a los títulos jurídicos de propiedad (...). Aparecen poderosos directivos particulares que dominan sectores enteros de la industria y sólo poseen en propiedad una mínima parte de las fábricas que dirigen. Este proceso económico trae consigo un cambio en la función del aparato jurídico y político, y de las ideologías. Sin que haya cambiado en lo más mínimo la definición jurídica de la propiedad, los propietarios se tornan cada vez más impotentes frente a los directivos y sus equipos (...). La influencia de la dirección, que en principio sólo se relacionaba con instancias jurídicas y administrativas inferiores, acaba extendiéndose también a las instancias superiores, y por último al Estado y su organización de poder" (Horkheimer, 2000: 69, 70).

La dirección, desprovista de medios de producción y de dominación, deja a los detentadores de los medios en condición de impotencia. Propietarios (en economía) y gobernantes (en política) pierden influencia. Que pueda no molestarles es tema para sicólogos. La dirección y sus recursos técnicos, su razón inexpugnable de la eficiencia y eficacia, controla los recursos bajo sus lógicas. Pero no es sólo control, es también la esperanza de que éste aumente, de que cada recurso sea crecientemente más dominado y de que no haya nada que no sea recurso. Weber no sabía qué profetas habían de erguirse en medio de este 'tremendo desarrollo', pero imaginaba que alguno habría. No imaginó (¿era posible hacerlo?) que la petrificación mecanizada no era el entorno donde saldría el profeta, sino que sería el profeta mismo (autonomía máxima de la racionalidad instrumental). La racionalidad del capitalismo, ya autónoma, se hizo ella misma promesa del carisma propio, sentido último de una historia que perdía el sentido. La tecnocracia es el profeta de su propia Modernidad, el fundamento mecánico de un capitalismo 'victorioso'.

Un economista de la prehistoria (cuando la economía, tiempos hoy espeluznantes y vergonzosos, se parecía a la filosofía) llamado Karl Marx, señalaba que hay un fenómeno que, cuando se produce, genera que las cosas más obvias sean omitidas y que diversas objetivaciones pasen inadvertidas. Llamaba a ese fenómeno ideología, falsa conciencia. Algo así ha de estar ocurriendo para que sea posible que la razón se vuelva nuevamente tan universal y hasta sea posible creer que los pajaritos actúan de acuerdo a la teoría de la elección racional. Y como se trata de decir cosas que tengan que ver unas con otras, habrá que señalar que ese fenómeno se relaciona con la tecnocracia, pues lentamente la razón técnica del economista está 'explicando el mundo'. El profeta siempre es una cara posible de la época que lo ha visto nacer. Si los hombres (y las mujeres, bueno) somos a imagen y semejanza de Dios padre, Freud dirá que odiamos y admiramos al padre en una trágica ambivalencia emocional. Y ritualmente lo comeremos, como acto de agresión, pero también de identificación (por eso las hostias, carne del padre). La tecnocracia es hija de la Modernidad, odia y admira al Gran Proyecto que la hizo posible. Pero, ya no ritualmente (otra pérdida de lo sustantivo es la ausencia de símbolos), se la está comiendo. 
La Modernidad ha estado llena de profetas. A estas alturas casi no hay proyecto que no se haya subido a la profecía de la Modernidad, bastión de racionalidad, inevitabilidad, legitimidad. Casi no hay proyecto de sociedad que no haya hecho a la Modernidad suya y que no haya hecho su proyecto como si fuese moderno. Una dialéctica en la identidad juega con la manoseada Modernidad. Ser moderno para ser o ser para ser moderno. Por eso Modernidad va con mayúsculas. Todavía.

Pero la pregunta sigue en pie. ¿Por qué decir que la tecnocracia es el falso profeta de la Modernidad? Para esto habrá que ver, primero, sobre profetas; luego sobre la Modernidad y finalmente sobre la tecnocracia. El orden puede alterar el producto porque el orden es el producto. Cierto es que la línea de argumentación se ve algo mecánica, tosca, pero no se puede hacer mucho: a todos nos toca algo de la jaula de hierro.

\section{De la Profecía}

Para hablar de profetas hay que referir a la ética religiosa, dicta Weber. La ética religiosa es, en el fondo, la forma en que la voluntad del hombre intenta converger con la voluntad de Dios. La contravención de la voluntad de Dios es pecado ético. La constitución de una ética religiosa (y ya el seguimiento a Weber va en tono de persecución) tiene como factores de sistematización al sacerdote y al profeta, formas de racionalización de ella. El profeta es nuestro tema, para que el título de este artículo no se crea sólo metáfora. "Con el nombre de 'profeta' queremos comprender aquí un puro portador personal de carisma, cuya misión anuncia una doctrina religiosa o un mandato divino" (Weber, 1996: 356). En términos políticos ${ }^{87}$, vale señalar que "es específico en los profetas que no reciben su misión por encargo de los hombres, sino que la usurpan" (Weber, 1996: 359). Pero la "falta de consideración' del profeta frente a los destinatarios de la profecía se enfrenta con el hecho de que él mismo es un instrumento de una divinidad cuya voluntad exige la obediencia. El poder del profeta está en ser instrumento de la divinidad.

Lejos los tecnócratas de la divinidad, se dirá. Sin embargo, ¿qué significa sociológicamente esta divinidad? Weber señala que en cualquier tipo de profecía la revelación profética (el mensaje divino) siempre significa, tanto para el profeta como para quienes le siguen, "una visión unitaria de la vida lograda por medio de una actitud consciente, de sentido unitario pleno, frente a ella. La vida y el mundo, los acontecimientos sociales y cósmicos tienen para el profeta un determinado 'sentido' sistemático único" (Weber, 1996: 363). En esta matriz fundamental, en donde está en juego el develar el sentido del mundo, yace el constructo central que históricamente dejaron los sacerdotes y profetas y desde el cual se habría construido la filosofía laica.

\footnotetext{
87 Nunca se insistirá demasiado en el peso político de la sociología de la religión weberiana. Y para reafirmarlo basta citarlo. "En su pleno desarrollo, las sociedades y comunidades religiosas pertenecen al tipo de las asociaciones de dominación" (Weber, 1998b: 261)
} 
Se quiere decir aquí que la tecnocracia ha sido profeta de la Modernidad y, además, falso profeta. Es decir, la tecnocracia ha usurpado -como un profeta- su misión y la ha impuesto a los hombres. Pero además ha construido un sentido pleno y unitario del mundo -tal y como lo haría un profeta-, sentido que lentamente va invadiendo nuevos terrenos. Ha comenzado por la economía, se ha trasladado a diversas ciencias sociales y lentamente busca imágenes de mundo más globales. La tecnocracia también anuncia una doctrina (la técnica) y un mandato divino (la inevitabilidad de la técnica) y, aunque no se porta personalmente el carisma, como debe ser en un profeta, no es menos cierto que la ciencia y la tecnología han desarrollado una gran capacidad para hacer uso del carisma, es decir, para llegar afectivamente, a partir de la acción extracotidiana, milagrosa, a la aceptación de las masas $\mathrm{y}$, subrepticiamente, a la legitimación de una dominación velada desde el saber. Y decir que hay dominación desde la técnica no tiene nada de raro. Ya Nietzsche decía que detrás de la razón estaba la voluntad de poder. Ya los teóricos críticos señalaron que la razón era más que nunca dominación. Ya se puede ver todos los días, privilegiados nosotros, que la técnica se hace método de exclusión de la política, de desviación de los problemas desde la esfera del poder político hacia la inmaculada y pequeña esfera del saber científico. Y el saber científico hoy está construido en un esquema de lo verosímil que no es otro que la economía comercial.

Supongamos que se acepta que la tecnocracia tiene rasgos de profeta. ¿Por qué falso profeta entonces? Un falso profeta es un profeta que no es. O que promete algo que no es, forma algo maliciosa de no ser profeta. Pero la sociología aceptará que, por un lado, no es su tema saber si efectivamente porta o no el mérito de la profecía y que, por otro, habrá que aceptar cualquier cosa que cumpla con las categorías sociológicas de profeta para hablar de tal. ¿Puede ser entonces falso profeta considerándose este relativismo sociológico? Por supuesto, pues puede estar profetizando el arribo, la llegada, la consecución de algo que no es. O puede portar el mensaje de algo que ya fue. O puede estar vulnerando la sustancia del mensaje sobre el cual se superpone. Una compleja interacción de todos estos factores parece, en este caso, hacer surgir el carácter de falso profeta de la tecnocracia. La tecnocracia promete la llegada de la Modernidad, el triunfo del proyecto tantas veces malherido en sus hegelianos avatares. La tecnocracia ofrece un camino según el cual la historia ha tenido la astucia, nuevamente, de acercarnos a la tan codiciada Modernidad. Pero lo que ofrece no es sino la misma y maltrecha Modernidad, la que nos tocó vivir, estéticamente reconstituida para ocultar los tortazos. Nos promete la reconstitución del sueño ilustrado, pero sólo nos dice que nuestra resignación es en realidad la felicidad. La tecnocracia ha vulnerado el sentido de la Modernidad y se ha constituido en profeta de la trayectoria desviada. Ha teñido de belleza la jaula de hierro weberiana, ha devuelto la eficiencia como un valor unidireccional y se ha enfrentado a la crítica de Horkheimer, de Adorno, de Marcuse, de Habermas y de tantos otros que sólo a veces no son alemanes.

De si es mejor o peor el sentido recto o el desviado, queda para otros ratos. Es un juicio de difícil resolución. Pero sí es muy claro que es desagradable que el sentido desviado pase por el recto. Eso solía llamarse ideología. Necesario es penetrar en estos asuntos para comprender el fenómeno de la tecnocracia, pero no en este texto. Aquí es aún necesario preguntarse qué será eso de desviar la Modernidad, si es que acaso es posible. Y surge también la pregunta de si acaso se puede estar seguro de que la tecnocracia se inserta en la Modernidad desviada. Alguien más exigente terminará diciendo, en la típica regresión 
interpretativa, “¿qué es la Modernidad?” La definición, siempre se vuelve a lo mismo. Un diccionario no basta a la ciencia, pero cómo nos gustaría que así fuese.

\section{De la Modernidad}

La Modernidad es, en primer lugar y en términos muy formales, la autorreferencia de una época nueva frente a lo viejo (es ese el sentido del término original modernus que tiene unos quince siglos). Como tal, muchas modernidades han existido (ver Habermas, 1985). Pero ninguna anterior quiso separar el pasado del futuro, siempre el primero fue 'maestro' del segundo (ver Koselleck, 1993). La Modernidad ilustrada sí soñó con esa distinción, según la cual esta Modernidad es ante todo proyecto y escasamente pasado.

Es cierto que la Modernidad ha sido asociada también a la forma cognitiva del descentramiento del mundo. Habermas ha tomado este concepto de Piaget y ha traspasado los conceptos de evolución cognitiva desde el sujeto hasta las sociedades. A través de la idea de un descentramiento se remite al fenómeno según el cual la experiencia del propio rol en la construcción de la realidad pasa a ser tematizada. Y eso no sólo lo dice Piaget. Lo dice también Marx de un modo más bello y más político. Y además no lo dijeron, pero lo hicieron, los revolucionarios de 1789 en Francia, en el momento de unión de la teoría y la praxis. Piaget señala también que una etapa cognitiva es la del surgimiento de la brecha entre acontecimiento y sujeto. Societalmente es el surgimiento de los problemas de la epistemología y, por tanto, del conocimiento. Habermas señala que la cultura resultante de fenómenos de descentramiento cognitivo (es decir, la moderna) goza de diferenciación a nivel de las categorías que permiten la labor argumentativa. Si en Platón lo bello, lo bueno y lo verdadero estaban vinculados, convergiendo sofisticadamente entre sí y relacionándose en el mundo de las ideas; en Kant lo bello, lo bueno y lo verdadero son criterios diferenciados, que merecen distinciones fundamentales (que incluso hay que remarcar con distintos libros para cada esfera). Esto es clásico del descentramiento, donde se asume la existencia de una distancia entre realidad e interpretación y que llega a expresarse en la lingüística con la agresiva tesis de que no hay vínculo alguno entre el significante y el significado.

Algunos paradigmas sociológicos han señalado que la Modernidad es el momento en que la coordinación de acciones, de manera simple, cara a cara, entra en crisis. Los criterios para coordinar acciones suponen un incremento en su racionalidad, generándose un nuevo modo de llevar a cabo dicha coordinación. Se trata del impersonal modo de los sistemas de acción. Este desarrollo conduce a nuevas formas organizacionales y, entre otros, supone el surgimiento del Estado moderno y la empresa capitalista. Las acciones de los actores deben coordinarse entonces no sólo entre sí, sino también (y a veces predominantemente) con el sistema. Y por eso ser moderno es, por ejemplo, ser impersonalista para las decisiones. $\mathrm{O}$ eso dijo Parsons.

La Modernidad es, también, el resultado de una serie de procesos como la industrialización, la urbanización y la explosión demográfica. Pero además es, si creemos en cierta inmanencia, la causa de estos procesos. Yo no creo en la inmanencia, pero basta que haya algunos que sí crean para que ella opere, lo que dicen que es el teorema de Thomas. Y 
como causa de esos procesos la inmanencia recurrida y más socorrida es la inmanencia de la razón, casi como el espíritu de la época. La Modernidad 'es' la razón en tanto 'es' su promesa, la buena nueva del advenimiento de la razón que de tanto deambular en la historia ha encontrado su sitio y se comienza a desplegar con todo su 'ser'. Y aquí entramos en el mensaje global, casi mítico, de la Modernidad.

La Modernidad, la que ha estado tan próxima a nosotros, es identidad y construcción de un proyecto, hacia el futuro, donde la razón finalmente llegaría a imperar. La historia tiene sus vicisitudes, su dialéctica, pero la Modernidad espera el momento casi religioso donde hayamos llegado a la razón, el momento donde no estemos equivocados, como una angustiante respuesta al 'juicio final' del judeocristianismo (juicio, que es palabra fuerte, pues es también crítica, razón; es decir, en la Modernidad vivimos entre dos juicios finales). Con la Modernidad se espera que el final sea no sólo feliz sino además tranquilo y permanente, que además sea de (y en) este mundo, que sea el punto quieto de una feliz racionalidad. Por eso la Modernidad es también una promesa. Todo proyecto lo es. Es la promesa del progreso. Los más radicales racionalistas trataron de negar el punto, haciéndolo menos tosco. Weber y Spencer, por ejemplo, descreyeron del asunto, detectaron el aspecto religioso de semejante esperanza. Pero Hegel y Marx de manera muy clara, Kant con más implícitos y toda la construcción teórica más cargada de politicidad explícita (liberalismo, socialismo) vislumbraron el punto final, más quieto o más móvil, con la forma de la utopía baconiana, con la verdad hecha carne y la sociedad moviéndose a su son. Pero no se trata de cualquier razón la que ha de triunfar. En la Modernidad encontramos la esperanza también de la plena constitución del sujeto político, donde se forma la autoconciencia de que en él reside la historia, que es ésta algo por construir, no un mero atavismo de tragedia griega. Es la esperanza de la autonomía y la emancipación.

En la Modernidad la razón está en el hombre, en los hombres (y las mujeres, para no ser patriarcal, aunque la Modernidad lo sea). La razón se deposita livianamente sobre los hombres para que sus decisiones la porten como una brújula que orienta sus acciones, hallazgos, pensamientos. La razón moderna -y éste es el punto- es sustantiva y formal, como lo era el sueño de la razón en la Ilustración. La profecía del progreso, del advenimiento de la razón, es el gran espíritu de la Modernidad. La tecnocracia se ha superpuesto a ese espíritu, pero lo ha desviado. Es una razón castradora, que reduce a escombros la amplia racionalidad del todo y se queda con la nimia racionalidad de la parte, que desplaza los problemas sustantivos y se queda con los operativos. Pero esto puede quedar sólo en atribuciones gratuitas si no se describe el fenómeno. La mecánica secuencia de este texto nos conduce a la tecnocracia.

\section{De la Tecnocracia}

Al caracterizar un fenómeno como la tecnocracia se ha de comenzar por una inútil distinción que sólo llegará a ser importante si el mundo se vuelve algo más complejo. La tecnocracia tiene características que le son contingentes y otras que le resultan necesarias. La tecnocracia, para ser tal, es siempre un grupo que participa en la distribución del poder, pero cuyas formas de acceso a la concentración de éste se fundamentan desde perspectivas 'técnicas' y no políticas. La fundamentación remite al problema de la legitimidad, es decir, 
al problema de si la verticalidad relacional entre actores y grupos puede justificarse por algún motivo y ser aceptada en razón a él por quienes son dominados. Sin embargo, en la tecnocracia no puede haber legitimidad. Incluso se puede apelar, en un discurso falaz y seudopositivista, a una legitimidad otorgada por la 'verdad' científica hecha razón técnica. Y alguien lo puede creer. Pero no hay legitimidad, pues el actor dominado no está aceptando jamás la dominación en sí, pues en la tecnocracia se omite el tema de las voluntades. La tecnocracia apela a que no se pueda decidir voluntariamente si estar o no de acuerdo, sólo se puede apreciar el resultado que operativamente la 'razón' ha señalado. La anulación del reino de la decisión y de la voluntad es parte del credo tecnocrático y de su lógica misma de justificación. Esto es, en la tecnocracia, permanente y necesario. Pero la tecnocracia podría ser razón técnica sociológica, económica, psicológica, comunicacional, lo que fuese. O podría ser la razón resultante de una sociedad donde el paradigma económico predominante fuese otro (pero ya no se me ocurren ejemplos, daño cognitivo resultante de la ideología). Es decir, el contenido teórico de un pensamiento tecnocrático es contingente.

¿Cómo es nuestra tecnocracia? La que hemos conocido es primordialmente económica. Y hoy es particularmente la que se basa en la economía comercial, cuya raíz teórica es la economía neoclásica. El mundo se ha empeñado, últimamente, en hacernos las cosas simples. Es cierto, por ejemplo, que una tecnocracia comunicacional rápidamente crece y se desarrolla en áreas del llamado marketing político. Pero aún no reciben ellos el estatus de tecnócratas, les falta mucha cientificidad según parece. Además, ellos son también resultado de la razón técnico-económica y sólo se abocan a que la cultura se adapte a los intereses y responda a las curvas de oferta y demanda. El marketing es sólo un subproducto de la economía, está en función a ella. Lo importante es entonces que nuestra tecnocracia contingente es económica y que se le suele describir ideológicamente como neoliberal o neoconservadora. Y es sublime que ese 'neo' sea lo permanente mientras se cambie de liberal a conservador y no importe (la razón no se complica con nebulosos valores). Porque en el 'neo' está la economía. 'Neo', que es 'nuevo'. 'Moderno', que también es 'lo nuevo'. La economía es lo moderno, lo inmutable e indiscutible, el destino de esta Modernidad.

En términos de tematización la convergencia conceptual entre lo necesario y lo contingente facilita las cosas, pues permite simplificar el modelo y trabajar con lo contingente y lo necesario juntos. Es la ventaja de hacer ciencia en entornos mítico-primitivos, diría un antropólogo. De hecho, qué más mítico que pensar que la convergencia de actores en el mercado supone un acto de autorregulación y mágico equilibrio que permite que todos resulten beneficiados. Qué más mítico que la mano invisible que guiaría los destinos del mercado. La idea de que el mundo está, se haga lo que se haga, en permanente equilibrio, es mítica, no moderna. Pero en fin, esto no define a la tecnocracia, sólo es algo que contingentemente los actuales tecnócratas piensan (y lo dicen con cara de científicos).

Decíamos que la tecnocracia ha de ser caracterizada, en primer término, como un grupo que participa en la distribución del poder en la sociedad. Habrá que señalar además que ostenta un claro 'ethos' y un tipo de posición que, estando vinculado al aparato público, se sitúa en una relación flexible con la institucionalidad del aparato de Estado. La conexión con el principal subsistema de la política, como es el Estado, deviene de la creciente necesidad de especialización que éste ha requerido para la toma de sus decisiones. La búsqueda de un 
mayor grado de racionalidad en términos de eficacia y eficiencia condujo al cuestionamiento del paradigma burocrático y a la revisión del mismo, pensándose en nuevas fórmulas. La búsqueda de una mejor capacidad operativa llevó a la pregunta por las formas de organización y tomas de decisión más 'acertadas' de acuerdo a los referidos fines últimos (la eficacia y la eficiencia).

El origen de la tendencia tecnocrática parece ostentar antecedentes desde distintos frentes. Quizás las primeras propuestas concretas, en el siglo XX, de algo parecido a la tecnocracia son las del pro-ingenieril sociólogo Thorsten Veblen, quien proponía una sociedad manejada por ingenieros. Recién pasado el año 1930, la cruel tradición humana de nombrar la ignominia para hacerla permanente y dolorosa hizo que se generara un neologismo. Se llamaba 'tecnócratas' a quienes merodeaban el aparato burocrático, pero que no estaban incluidos en él (y por tanto no gozaban de ese prestigio). El arribo de técnicos externos se hizo más frecuente en el keynesianismo, pues sus complejidades teóricas requerían de profesionales expertos, lo que condujo a la construcción de cierto prestigio para los economistas. Esta genealogía no pretende ser exhaustiva, pues lo que de todo esto sí resulta relevante es que el camino de desarrollo de un pensamiento tecnocrático fue rápidamente asimilado a las convergencias ideológicas. Por la época, casi no quedaban especialistas que no reivindicaran las propuestas keynesianas y el Estado social. De hecho, en un congreso titulado "El futuro de la libertad" desarrollado en Milán en 1955, más de 150 intelectuales de distintas nacionalidades y de casi todas las posturas ideológicas (salvo comunistas), se dieron cita y llegaron a la conclusión de que las diferencias ideológicas se habían reducido ostensiblemente, lo que era tan evidente que ellos mismos estaban de acuerdo en todos los aspectos centrales. El único que no estaba de acuerdo con las conclusiones del congreso era Frederick von Hayek. Y el consenso estaba construido respecto a las políticas de los Estados de bienestar. De hecho, en el mencionado congreso, "todos concordaban (menos Hayek) en que el aumento de control estatal, manifestado en varios países, no concluiría en una disminución de la libertad democrática" (Lipset, 1987: 358). Y las únicas discrepancias que persistían eran leves diferencias entre los niveles de planificación estatal considerados deseables por la izquierda y la derecha. Fue precisamente en este congreso donde se terminó hablando del 'fin de las ideologías', pues se consideró evidente que prontamente se llegarían a acuerdos universales. En este marco de confluencias, los tecnócratas encontraban campo fértil: la ausencia de discusión ideológica, les parecía, favorecía el trabajo técnico, que sólo opera en marcos de reducción de complejidad.

Paralelo a este proceso de penetración de la técnica en la política, la relevancia del Estado como sistema central de la vida social abría las necesidades de respuestas a las inquietudes sobre su propio funcionamiento. Este proceso supuso nuevos planteamientos y propuestas. Finalmente, una de las vías fue el creciente acceso de un particular tipo de especialista muy similar al 'director' de las corporaciones privadas de corte empresarial. Los directores nacen con las sociedades de acciones y se posicionan como las personas a cargo de administrar una propiedad con la 'ética' de quién la posee, pero sin tenerla materialmente. Entre el dueño de los medios de producción y quien vende su fuerza de trabajo, se sitúa el gerente que es en cierto sentido ambas cosas y que, en rigor, no es ninguna. De manera similar, en el aparato de Estado comienzan a arribar actores que no tienen legitimidad para poseer los medios de dominación (no son representantes) y a su vez no tienen orientado su trabajo por las órdenes de los dominadores (no son funcionarios). La tecnocracia finalmente será un 
término cuya ampliación histórica referirá a esta clase de individuos que -como dirá Touraine- distienden el equipo y el servicio (Touraine, 1973).

A medida que el keynesianismo perdía relevancia, los tecnócratas keynesianos se fueron extinguiendo. Las propuestas neoclásicas en economía intentaron (con bastante éxito a la larga) ser el paradigma económico predominante. Y desde su seno formativo emergieron también tecnócratas, pero esta vez con pretensiones de estar más cerca de la clase política y con un afán de prestigio social mucho más ambicioso. Con una mezcla de razonamientos positivistas, sistémicos y neoclásicos, unidos a la innovación de que la economía misma podía ser un discurso político; la tecnocracia logra situarse como un grupo portador de una verdad que supera la mera opinión fundamentada. Es mucho más que el intelectual y crecientemente más que el asesor. De hecho, obtiene con relativa rapidez cierta capacidad de decisión. Y ella deriva de una asociación clave: el vínculo entre la medida técnicamente válida con la presunción de que la decisión es científicamente elaborable. De este modo, en el paradigma tecnocrático, la decisión es perfectamente reductible a racionalidad. Y, específicamente, a racionalidad instrumental. Se trata de una conjunción del concepto más fuerte del positivismo con el más contundente del utilitarismo. La verdad y la utilidad están en juego y, ante esto, hay especialistas capaces de dar cuenta de ambas. Es ese el 'credo' tecnocrático.

Como toda estructuración del pensar, las posturas tecnocráticas ostentan una serie de premisas fundamentales. Según García Pelayo (1974), la tecnocracia tiene como supuestos:

1- la imagen del Estado, de la sociedad global y de las sociedades sectoriales como sistemas $^{88}$. Sólo en base a esta premisa la tecnocracia supone que una medida tomada en un factor tendrá efecto en otro, efecto además predecible si pensamos que todo 'sistema' tiene una lógica 'sistematizable'.

2- la convicción de que tales sistemas 'deben' ser orientados según los principios de la razón técnica. Esta premisa es central. Más abajo, en el apartado sobre racionalidad se verá que a la técnica le subyace la racionalidad medios-fines, la racionalidad acuñada como instrumental. Esto implica que toda sociedad, ya que es entendible como sistema en el paradigma tecnocrático, 'debe' estar orientada en términos instrumentales.

3- el argumento de que los conocimientos adecuados a la dirección del Estado son proporcionados por disciplinas cuyas conclusiones son válidas y aplicables a distintos sistemas. Esta premisa nos conduce a un terreno más que interesante. Si los conocimientos de la conducción del Estado son entregados por muy diversas disciplinas que a su vez pueden tomar sus observaciones y extrapolarlas a otras dimensiones de la vida social, hallamos que se anula la distinción operativa entre aparato de Estado y sociedad. Los saberes no distinguen fronteras ni las requieren. La burocracia jamás extrapoló sus saberes al resto de la sociedad. La tecnocracia supone esa posibilidad.

\footnotetext{
${ }^{88}$ En la presente enumeración se anotarán en cursivas las síntesis de las premisas detectadas por García
} Pelayo. En grafía normal se harán comentarios. 
4- la imagen de que para cada problema existe una solución óptima, con lo cual se evitan discrepancias. Esta premisa es clave. Supone el grado más alto de racionalidad y conecta con las teorías de toma de decisiones.

5- La recomendación de que la estructura politico-institucional debe adaptarse a las exigencias de la razón técnica.

El punto 3 es uno de los más importantes a la hora de analizar el pensamiento tecnocrático. Las ideas de organicidad social recorren la historia de la sociología (con mucha fuerza desde Spencer), pero su evolución muestra diferencias y cambios importantes. Para Lyotard, la idea de que la sociedad forma un todo orgánico era una convicción que dominaba el espíritu de los fundadores de la escuela francesa de sociología. Pero este aspecto adquiere nuevos énfasis y nuevas precisiones con el funcionalismo, ante todo cuando Parsons, en los años cincuenta, asimila la sociedad a un sistema autorregulado. El modelo teórico deja de ser el organismo vivo y pasa a ser la cibernética. Para Lyotard, el principio del concepto de sistema en Parsons es todavía optimista, pues corresponde a la estabilización de economías en crecimiento y abundancia. En los teóricos alemanes de hoy (se refiere básicamente a Luhmann), la teoría de sistemas es derechamente tecnocrática (más aún, 'cínica', dirá Lyotard). La armonía entre necesidades o esperanzas de individuos o grupos respecto a las funciones que asegura el sistema es una relación secundaria, adjunta. La fiabilidad del sistema sólo radica en la optimización, en la performatividad. Pase lo que pase (y el relativismo es aquí paradójicamente absoluto), todo es un reajuste interno y el resultado no puede ser sino la mejora en la vida del sistema. De cualquier modo, el fundamento último del pensamiento tecnocrático permanece en la tradición spenceriana y persiste en Parsons y en Luhmann: se trata de la idea de que la sociedad es una totalidad funcionalmente unida. El estado del sistema debe considerarse como un todo, como dirá Parsons, donde un proceso conjunto de condiciones hace más desarrollado al sistema o resulta disfuncional a la eficiencia del mismo. Esta idea es también compartida por los tecnócratas, dirá Lyotard, de ahí su credibilidad, pues cuentan con la posibilidad de administrar las pruebas, debido a su doble posición técnica y política (Lyotard, 1995).

Otra caracterización clásica en la materia es la de Jean Meynaud (véase textos de 1965 y 1968), quien entiende por tecnocracia una forma de estructurar el poder de manera tal que los técnicos condicionan o determinan la toma de decisiones, tendiendo así a sustituir al político en la fijación de 'políticas' y a los burócratas en la puesta en operación de las decisiones. En este sentido, 'tecnocracia' es una nueva clase política. Sin embargo, la forma de uso del poder no sería semejante a la del político, como señalará Touraine, pues la acción del tecnócrata no es de mando, es de manipulación

"los tecnócratas no son técnicos, sino dirigentes, pertenezcan a la administración del Estado o a grandes empresas estrechamente vinculadas, siquiera por su importancia, a los ambientes de decisión política. Solamente en este sentido puede hablarse de una 'élite del poder'" (Touraine, 1973: 53).

A la hora de caracterizar la dominación del 'tecnócrata', Touraine dirá que no es directa ni clara: es ambivalente. Esta conjunción es decisiva. Se trata de una elite de poder que actúa 
de manera indirecta, cuya forma de acceso al control radica en su vínculo socialmente aceptado con el saber, la expertiz.

Lo cierto es que todas estas características de la tecnocracia requieren quedar superpuestas a condiciones socioculturales que permitan su arribo a ser parte de la clase dirigente. Es cierto que la conversión de la decisión en una cuestión técnica está a la par con la posibilidad (conceptualmente hablando y no necesariamente de manera histórica) de que el técnico adquiera una relevancia antes insospechada. Sin embargo, no es menos cierto que el tipo de tecnocracia existente ha de adaptarse al tipo de decisiones que son consideradas sustantivas para los destinos de la sociedad. Y, fundamentalmente, se requiere que las capas dominantes sean permeables a la operatividad tecnocrática (pues finalmente las ideas dominantes de una sociedad son las ideas de la clase dominante). Y en este punto es donde el tecnócrata actual, economista comercial, encuentra el terreno muy fértil para sus propuestas en las condiciones actuales del capitalismo. Después de todo, el hecho de ser quienes (se supone) saben cómo hacer la riqueza, cómo administrarla, cómo hacerla crecer; les convierte en portadores de un saber fundamental, sobre todo considerando sociedades donde el acceso al mercado es eje de la jerarquía social y donde, por tanto, la riqueza es valor supremo. La pregunta sobre cómo hacer riqueza ha sido traducida mecánicamente en la pregunta sobre cómo generar desarrollo, como si para pasar de lo privado a lo público bastase un chasqueo de los dedos. Se pasa de la organización productiva a la asociación de dominación sin problemas, con la misma forma de construcción de índices y de evaluación de decisiones. La racionalidad del mercado se hace, así, razón de Estado.

Sin embargo, el acceso del tecnócrata al Estado suponía una propuesta de análisis e intervención en la sociedad que requería de aceptación. En este proceso es posible detallar algunos discursos de legitimación que serán sintetizados más abajo. Pero hay una necesidad previa: para que un paradigma científico predominante (que ha logrado imponerse en su medio a partir de la instalación de algunos problemas como los más sustantivos de la disciplina) pueda extrapolarse a un paradigma de conducción de la sociedad, resulta indispensable vincular ciertos aspectos sustantivos del paradigma con cuestiones de referencia general en la sociedad. Es decir, el paradigma debe ostentar algún nivel de predominio como imagen de mundo. Y si bien la descripción de este proceso sería larga y engorrosa de detallar, considerando además que no está en los objetivos de este texto; es posible reducir las expectativas a la mera descripción de esa imagen del mundo, en este caso, de la sociedad.

El tecnócrata ha logrado dar cuenta de las sociedades y sus instituciones como sistemas, en los que predominan ciertas lógicas operativas que, de ser conocidas, (se asume) pueden ser manipuladas. En este marco, los sistemas 'deben' ser orientados según los principios de la razón técnica (el 'deben' no es normativo, está en calidad de poder fáctico). La búsqueda de óptimos específicos y acotados conduce necesariamente a la optimización de la sociedad toda. Por demás, el Estado es un sistema como cualquier otro. Y lo que es regla para los distintos sistemas, como la empresa capitalista, es válido para el Estado, se asume. Por esto es que la dirección del Estado debe ser realizada desde los mismos ejes que la empresa, lo que indica a la economía como la disciplina sustantiva. Más aún, la disciplina que se ocupe debe ser utilizada en razón a su grado de univocidad, pues existe sólo un óptimo y por tanto no deben haber respuestas discrepantes. Es por esto que la disciplina a cargo de la 
resolución de problemas debe usar modelos claros y precisos, carentes de grandes diferencias unos de otros. La unanimidad es considerada prueba de la sensatez de la disciplina. Y esto supone la conversión de dicha disciplina en una técnica (la técnica es ella misma razón instrumental, es decir, la búsqueda del mejor camino para un fin), en este caso, la conversión de la economía en economía aplicada de corte comercial. Finalmente, como corolario, la razón técnica debe ser el fundamento de la estructuración institucional y política de la sociedad, es decir, el diseño de ésta debe responder a los objetivos de optimización económica que señala la disciplina cuya lógica impera.

Importante resulta destacar que el acceso de la tecnocracia modifica la forma específica del Estado moderno. En éste, la separación entre dirigente y funcionario era seguida por la diferencia entre representante (que toma la decisión) y especialista (que señala las posibles consecuencias de las distintas acciones al representante). Sin embargo, el tecnócrata es dirigente, pero no es representante; $y$ es especialista, pero no es funcionario. Y no es funcionario porque en parte la naturaleza del tecnócrata exige cierta ausencia de formalidad en su inserción en el aparato de dominación. Para que el especialista pueda decidir en el Estado moderno, no puede ser funcionario, pues estos tienen claras delimitaciones de funciones desde el ámbito jurídico, muy rígidas e imperativas, con explícitas y continuas jerarquías, además de roles permanentes. Por demás, el mero funcionario, hasta hoy, está supeditado a la decisión voluntarista del político, lo que para el tecnócrata sencillamente vulnera el espíritu de su racionalidad (más aún, vulnera el espíritu de la Razón).

Ahora bien. Aunque es cierto que ser tecnócrata supone ubicarse fuera de la institucionalidad permanente, no es menos cierto que la burocracia típicamente moderna propia de la administración pública le resulta un obstáculo. Básicamente es la diferencia de cultura organizacional entre el tecnócrata y el burócrata la que complejiza la imposición del paradigma tecnocratizado. En este sentido, la tecnocracia ha cuestionado fuertemente la administración pública, a la que ha catalogado de 'tradicional' (notable fórmula de oponerla a Modernidad) y ha propuesto un nuevo paradigma, una Nueva Gerencia Pública que sea concomitante al desarrollo de un proyecto de modernización del Estado.

El tecnócrata construye un discurso donde el político es visto como un actor público cuya relevancia decisional debe ser baja por su fuerte diletantismo. Por demás, la política misma es apreciada como un espacio de meras luchas de poder entre intereses personales, donde se dirimen cuotas de poder y cuyas lógicas de operación están lejos de la racionalidad (lo que además muchos políticos se empeñan en confirmarlo). Por otro lado, el burócrata queda señalado como un especialista de corte ineficiente, de baja preparación y muy apegado a reglas excesivamente estrictas que (supuestamente) quitan capacidad ejecutora.

Por supuesto, el tecnócrata no es el tipo que tiene un pie en la técnica y otro en la política. El tecnócrata es el técnico que es capaz de tener capacidad operativa y de toma de decisiones en razón de sus argumentos técnicos, siendo capaz de imponerlos ante diversos otros argumentos. Es este el fenómeno de la tecnocracia. La cooptación del técnico por la actividad política es accesoria y no aporta al análisis de este tema (aunque sí al análisis de las elites). 
Son éstas, someramente, las bases del pensamiento e imaginario tecnocrático. Pero estas bases han de plasmarse políticamente, han de ser proyecto. Y lo han sido. Desde el imaginario tecnocrático una serie de razonamientos se han construido. El gran antagonista explícito o implícito es la política. Eso se puede apreciar en cualquier discurso protecnocrático $^{89}$. La escasez de un estatus claro de racionalidad de la política como actividad ha sido, en parte importante, el espacio abierto a la crítica tecnocrática. El desapego de la ciencia política respecto a los problemas de racionalidad y su esquiva mirada, hasta resentida a veces, hacia la sociología, donde dicho tema sí es eje; parecen ser factores que favorecen la crítica respecto a la política como actividad o como problemática que carecería de un estatus claro respecto a la racionalidad. Y es así como se ha construido un argumento que señala que el pensamiento ideológico (no en el sentido marxista, sino como doctrinas políticas o, más en general, como tematización del orden social), propiamente político, estaría en un nivel muy bajo -y hasta indefinible- de racionalidad. Y es así también como se ha aceptado la idea de que la política debe 'modernizarse'. Incluso esta idea ha sido absorbida por algunos círculos politológicos que, indirecta o directamente, reconocieron (en prueba de ignorancia) la necesidad de tecnocratizar las decisiones, quedando la política resumida sólo a la mera lucha por cuotas de poder en aparatos donde lo sustantivo aparece como ya decidido.

\section{De la razón tecnocrática y la falsa profecía.}

En el mundo de la jaula de hierro weberiana no cabe nada sustantivo. ¿Cómo llegar desde la pérdida de la sustancia a la profecía? ¿Cómo pasar de la profecía de lo extracotidiano a la profecía de la norma estadística? El proceso no parece ser asible de buenas a primeras. Pero desde el tibio idealismo se pueden hacer algunas intentonas. La descripción weberiana de la jaula de hierro cuestiona el sentido de la historia y la autonomía del hombre en ella. De este modo la jaula nos plantea una interesante paradoja al cuestionar tanto la matriz premoderna de comprensión de la historia (el mundo tiene un sentido trascendente) como la moderna (la historia la construyen los hombres, quienes pueden darse sus propias reglas). Lo que la jaula de hierro 'ofrece' a cambio es la irrelevancia de la voluntad y el mecánico trayecto de una razón operativa. En la medida en que se logra prescindir del uso de la voluntad en medio de la racionalidad, se promete el camino de la Modernidad. Ella, la Modernidad, ha perdido su sentido político. La decisión pierde valor en tanto se asimila a arbitrariedad y dogmatismo, quedando en el lado opuesto a la razón. Al poder se le distancia de la probabilidad de que alguna voluntad se imponga a otra en el marco de una relación social. En cambio, el poder comienza a quedar definido desde la razón instrumental: es el poder del 'disponer', del control, del manejo y la predicción de rendimientos de determinados recursos. En este nuevo marco la ausencia de actores conduce al poder como una operación. $\mathrm{Y}$ es aquí donde es posible una profecía hecha de curvas normales.

La resolución idealista nos deja sin actores. Es como si no existieran los tecnócratas, como si no hubiera politicidad en medio del proceso de imposición de una forma de la razón. Podríamos recurrir (y debemos hacerlo aunque sea como matiz) a una mirada algo más

\footnotetext{
${ }^{89} \mathrm{Al}$ respecto se puede ver la ya referida tesis, homónima a este artículo, donde se revisan algunos discursos protecnocráticos.
} 
materialista (aunque este texto ya se graduó de idealismo). Pero es necesario ir con cuidado. Una burda resolución materialista podría conducirnos a la hipótesis conspirativa de una clase dominante que consuma su posición con una aséptica mecanización. Y, sin embargo, hasta esta burda interpretación merece atención. Entonces, aparentemente se requiere avanzar en medio de ambas interpretaciones (la materialista y la idealista). Por un lado, la mecanización de una jaula de hierro como el sino de una formación histórica (capitalismo) nos puede conducir a la pérdida de los actores. Pero, quizás por lo mismo, permite comprender las líneas gruesas de un proceso. En parte entonces el trabajo 'idealista' permite llegar a buen puerto aunque nos basemos en el sofisma de un 'desenvolvimiento' de procesos históricos. Por otro lado, sí hay actos de construcción de hegemonía que han sido sustantivos para la tecnocratización. Se pueden mencionar, por ejemplo, desde un tipo de formación profesional y académica que niega los debates paradigmáticos en la disciplina eje (la economía) hasta las específicas formas en que se invaden las esferas de la decisión política con una teoría de la toma de decisiones. Estos ejemplos no agotan los aspectos concretos que toman las dinámicas tecnocráticas, cuyos correlatos se pueden hallar en las más diversas expresiones de la vida social.

La lucha de paradigmas en las ciencias es siempre una lucha política. Esto se hace muy claro cuando se aprecia que la economía (ya subyugados los debates en su interior) intenta y logra avanzar hacia otras disciplinas gracias a la construcción de un marco metodológico general (el individualismo metodológico). A través de ese marco la premisa individualista de que el actor elige racionalmente (es decir, se asume, en su propio beneficio) ante la coyuntura de una decisión cualquiera, se proyecta como modelo de comprensión general de los fenómenos. Este proceso, el traslado de una imagen de mundo a una norma lógica y metodológica sumamente restrictiva, no es un evento menor. En el fondo se trata del proceso por el cual una imagen de mundo se proyecta a la categoría de modo de pensar. Y un fenómeno de esta índole sólo puede haberse producido si esa imagen de mundo es portada por quienes son capaces de imponerla con éxito, la clase dominante, el grupo que ha visto que sus intereses se satisfacen avanzando por los derroteros de una forma de ver el mundo. La dominación se consuma con una imagen de mundo adecuada y los actores quedan incapacitados para imaginar siquiera alguna fórmula alternativa. Nos convencemos incluso que decidir es confrontarnos con un 'mercado' de alternativas mentales. La forma de pensar supone imponer determinados fines últimos, horizontes de posibilidad, bienes de salvación. La dominación se ha hecho hierocrática en el sentido weberiano.

Desde un aparentemente inofensivo principio metodológico (el individualismo metodológico) los tecnócratas han constituido una imagen de mundo. Y, desde ella, se ha llegado a la fórmula política, a la construcción de un discurso de legitimación. ¿Cómo se produce este salto? Se propone, aquí y ahora, a la profecía como fenómeno capaz de realizar este paso fundamental. Weber, en sus ensayos de sociología de la religión, señala que toda profecía está enfocada en los desgraciados o amenazados. La búsqueda de redención es propia de los oprimidos. Sin embargo, quienes portan la profecía, sus constructores, no son los oprimidos: "por lo general, el profeta mismo no era en absoluto descendiente o representante de las clases oprimidas. Veremos que es más bien lo contrario lo que constituye casi una regla." (Weber, 1998b: 240). La profecía tecnocrática viene de una clase en tanto es portada por un grupo cuya situación de aprovisionamiento y adquisición está determinada por un tipo de destreza "en el ejercicio de funciones 
codiciadas" (Weber, 1998b: 267). De la situación de clase ha derivado una situación estamental fundamentada en un honor social resultante de un estilo de vida, una cierta clase de adquisición educacional, un concepto de prestigio y unas oportunidades económicas jurídicamente monopolizadas. De este modo, el 'sujeto histórico' decisivo de la promesa tecnocrática (el economista comercial o equivalente con participación en el mundo público) define el particular 'bien de salvación' de esta profecía. Los bienes de salvación pueden ser mundanos o extramundanos. La profunda vinculación con el mundo del sujeto histórico central de la profecía tecnocrática hace que su bien de salvación sea eminentemente mundano. Se trata del eje riqueza-desarrollo, bien de salvación que en tanto 'riqueza' ha sido el de muchas profecías mundanas (uno de los más comunes junto a la salud, la longevidad, la liberación del sufrimiento y la evitación de la muerte). Lentamente el eje de la comprensión del mundo de la clase tecnocrática se adapta a motivos específicamente plebeyos (en un sentido nietzscheano, si se quiere), es decir, se hace legítimo.

Weber, haciéndose cargo de Marx, ha dicho que "son los intereses, materiales o ideales, no las ideas, quienes dominan inmediatamente la acción de los hombres. Pero las 'imágenes de mundo' creadas por las 'ideas' han determinado, con gran frecuencia (...), los raíles en los que la acción se ve empujada por la dinámica de los intereses” (Weber, 1998b: 247). La profecía, como promesa, es una apelación a una imagen de mundo posible, futura, deseada. Detrás de ella han de haber intereses. La profecía tecnocrática actual está obviamente sustentada en una base de intereses. No hay que apelar a un burdo mecanicismo que nos conduciría a la tautológica observación de que tras la profecía tecnocrática está la tecnocracia como clase. Estando ella en una situación de intereses muy clara, que permite entender su doctrina y su promesa, no es menos razonable que sea ella misma el resultado de otra constelación de intereses y de otra imagen de mundo. Foucault ha señalado que para la constitución de una disciplina es necesario primero abrir esa posibilidad 'discursiva' (Foucault, 1996). Y la posibilidad discursiva de la economía actual tuvo un desarrollo originario en la constitución de un 'ethos' adaptado al capitalismo, el mismo que Weber estudia minuciosamente en gran parte de sus obras (y específicamente en "La Ética Protestante y el Espíritu del Capitalismo"). En este marco, las dinámicas tecnocráticas actuales no parecen responder a lógicas demasiado diferentes a las que describe el capitalismo y su jaula de hierro a la racionalidad.

Puede resultar paradójico que la razón instrumental del capitalismo victorioso se tiña de profecía religiosa. Pero una visión política de esto anula la paradoja:

"en su pleno desarrollo, las sociedades y comunidades religiosas pertenecen al tipo de las asociaciones de dominación: representan asociaciones 'hierocráticas', es decir, aquellas en las que el poder de dominación se apoya en el monopolio de la administración o la negación de bienes de salvación" (Weber, 1998b:261).

La promesa de la economía como disciplina respecto de unos bienes de salvación específicos, como ‘desarrollo' (para lo público) y 'riqueza' (para lo privado), es el eje de la construcción de un imaginario detrás del predominio político. Pero todo proceso de legitimación es más complejo y pone en juego el problema del mérito del dominio. Para el caso, debido a la pretensión cientificista de la tecnocracia, sus discursos han debido hacerse 
cargo del debate teórico. Es decir, el discurso tecnocrático, por sus propias pretensiones, exige discursos de legitimación con un cariz científico.

En este sentido es posible detectar dos discursos teóricos de legitimación de la tecnocratización que resultan consolidados: se trata del discurso de que la técnica es superior en racionalidad a la ideología y que por tanto el uso de criterios técnicos hace más racional, por tanto moderno, al Estado y la política. El otro discurso es, en parte, subsidiario del primero. Señala que con vista en las problemáticas organizacionales y de eficiencia en el Estado, éste requiere una 'modernización', donde el incremento en la expertiz de los funcionarios y el uso de un nuevo marco organizacional permitirá incrementar los niveles de eficiencia, tal y como ha sido posible de realizar desde hace ya años en el 'sector privado' (el mercado). Son estos los principales discursos teóricos de legitimación de la tecnocracia.

Veamos el primer punto. La pretensión de una racionalidad superior en la técnica que debe reemplazar a la ideología como forma empobrecida de racionalidad ha sido señalada durante el siglo XX con distintas intensidades. Desde Veblen en adelante la fuerza de esta idea tuvo momentos más y menos felices. Pero ya a fines del siglo XX el surgimiento de Francis Fukuyama revitalizó la postura. En una arriesgada maniobra, tomando a Hegel y cierta parte de las ideas marxistas, con un desarrollo muy hábil y con una lectura de la Historia Universal asumida con un Sentido (así, con mayúsculas), Fukuyama terminó diciendo que los hechos acaecidos recientemente, como la caída de los socialismos reales, como el triunfo de las ciencias en (y con) el capitalismo y la convergencia de puntos de vista sobre dicho modelo económico; revelaban inequívocamente el 'fin de la historia'. No se trata de que se acaben los hechos y las cosas. Pero los grandes procesos han llegado a su fin, el reino de la contingencia se ha acabado pues al llegar al punto cúlmine de la razón se ha construido el reino de la necesidad en este mundo. Ante esto, la ideología que siempre es discusión y poco acuerdo, que opera bajo la premisa de que los distintos grupos tienen premisas distintas, ha de acabarse. Más aún, se acabó. El argumento del fín de las ideologías era ahora argumentado desde Hegel. La Modernidad había llegado a su final.

Respecto al segundo punto, el argumento sobre la modernización del Estado, se puede señalar que las lógicas tecnocráticas son confirmadas, respaldadas y reproducidas en proyectos como el que hoy se denomina bajo el rótulo de 'modernización el Estado. Debe señalarse la fuerte ausencia de potencia y articulación conceptual de la teoría sobre la modernización del Estado, lo que entre otras cosas desmiente su fuerza en racionalidad. Más aún, sólo un aspecto específico de este proyecto, como es la construcción de un nuevo tipo de funcionario público (el Nuevo Gerente Público) cuenta con una teorización más elaborada, aunque no es sano señalar que se trata de una construcción demasiado consistente. Lo cierto es que el marco teórico de la Nueva Gerencia Pública es una excelente fuente de legitimación de la tecnocracia, pues resulta evidente que el 'ethos' detrás de esta nueva gerencia pública responde al imaginario tecnocrático. De este modo, el actor clave de la reforma del Estado, es decir, el funcionario público del nuevo paradigma, no hace sino establecer criterios de operatoria general similares a los de la operatoria tecnocrática. El tecnócrata deja de tener un vínculo extraordinario con el Estado y se transforma en parte de la rutina. Weber decía que la dominación es cotidianamente, ante todo, administración. La tecnocracia, con su inserción al nivel del funcionariado interno, 
gana esta dominación cotidiana, destruyendo el 'ethos' tecnocrático. Su lógica comienza a penetrar la organización misma y no sólo las decisiones hacia la vida social.

La modernización del Estado y la búsqueda de un cambio de actor nuclear en la administración pública (del burócrata al gerente público) tienen como dimensiones principales la flexibilidad en la toma de decisiones, la discrecionalidad del funcionariado, la búsqueda de eficacia y eficiencia, además de una mayor proximidad a la ciudadanía en tanto 'usuarios' de aquellos servicios que, por fallas de mercado, quedan en manos del Estado. Hay aquí un desplazamiento y no una mera reducción de dimensiones y aspectos. Es el desplazamiento de la política entendida como gestión de gobierno y del gobierno entendido como gestión administrativa. Hasta aquí el desplazamiento no es tan pronunciado como sí lo es el énfasis en aspectos ya existentes. Sin embargo, el tema radica en que el modelo de racionalidad que opera es el del mercado. La administración pública ha de ser como si no fuera pública. De hecho, debe hacerlo como si fuera privada. Notablemente, se reproduce el fenómeno que ha sido reiterado sobre el origen posible de la tecnocracia, como desplazamiento de las dinámicas gerenciales en las empresas privadas hacia el sector público. La lógica de la política, entonces, pasa a ser la lógica de las constelaciones de intereses, como diría Weber para señalar al mercado. Estamos en la carencia de legitimidad, en la mera búsqueda del óptimo. Y mejor que la política sea políticas públicas, la economía de los pobres ${ }^{90}$.

Respecto al discurso de legitimación no teórico, es éste extremadamente simple. Siendo la ciencia el vínculo de los hombres con la verdad, entonces la técnica, que no sería otra cosa que la aplicación de la ciencia, debe ser la que provea los criterios (verdaderos) de decisión en la vida social. Pues "la razón es el más noble instrumento terrenal, la ciencia es el producto propio de la razón y la técnica es la ciencia aplicada" (Fernández de la Mora, 1968: 147). Como se ve, este discurso 'no teórico', igual se ha manifestado 'teóricamente'.

La tecnocracia trae la profecía del fin de las incertidumbres, del imperio de la razón. Se pretende la utopía moderna hecha carne, el control del reino de este mundo. La Modernidad había soñado con este momento de unión con la Razón, como esas muchachas que sólo esperan el día en que se casarán, y aunque la razón no era eso que se pensaba, esa mágica conjunción entre lo sustantivo y lo formal, sino una cosa más parecida a una jaula de hierro, no ha quedado otra que aceptarlo, como tantas otras novias que ocultarán su frustración en el hecho de portar el vestido de princesa.

La tecnocracia es el profeta, hace el llamado al nuevo mundo, trae la buena nueva, pero es también ella misma la profecía. Lentamente crecen sus sacerdotes, sus gerentes públicos y otros portadores de las interpretaciones correctas. Sin embargo, hace tiempo ya que

\footnotetext{
${ }^{90}$ En la investigación que fundamenta este artículo se detectó que en los programas discursivos de los actores políticos protecnocráticos las políticas públicas surgen como un ámbito disciplinario que debe ser capaz de usar los mismos métodos de la economía. Pero se han de usar para analizar el problema de la pobreza (que se asumen excluidos de la economía). Esto se universaliza en la medida que lentamente se significa, casi sinonímicamente, a las políticas sociales con las políticas públicas. Se atribuye así, en implícito, que la economía es la ciencia de la riqueza, lo que no es extraño en la medida en que la tradición del liberalismo económico reconoce el origen de esta ciencia en la obra "Un Examen de la Naturaleza y las Causas de la

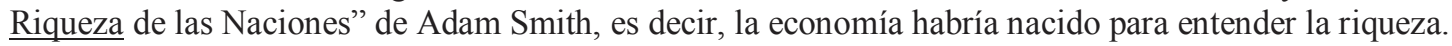


tenemos a la razón instrumental por doquier dispersa. Hace rato que el capitalismo ha construido sus leyes de la racionalidad y las ha hecho carne. Hace rato vivimos en la jaula de hierro y hace rato que la dialéctica de la Ilustración ya ni siquiera alcanza para tesis y antítesis. Este profeta ha llegado para anunciar lo ya ocurrido y teñirlo como un futuro de esperanza. Este profeta es un falso profeta.

A mediados de siglo Marcuse declaraba que a pesar de que "la totalidad parece tener el aspecto mismo de la Razón (...) esta sociedad es irracional como totalidad" (Marcuse, 1968: 11). El fenómeno tecnocrático parece situarse en este mismo marco conceptual. Es éste la aparente objetivación de la racionalidad, pero una revisión en determinados niveles de análisis desnuda otros componentes, no sólo distintos, sino hasta opuestos. En su origen, el espíritu de la Modernidad se depositaba sutilmente sobre la Razón y ella envolvía suavemente al Hombre. El apócrifo evangelio del tecnócrata carece del espíritu y mantiene las palabras, haciendo de ellas una profecía inevitable.

Se señaló que dos son los grandes rasgos de un profeta. Es él la objetivación de una promesa o una amenaza, pero también es quien certifica que el pronóstico tiene una base, que se puede invocar al destino. Ya Weber veía en 1919 que a la ciencia le exigían rasgos de profeta y escépticamente pedía que quienes necesitaban de profecías en sus vidas, volvieran a las viejas iglesias. Hoy el tecnócrata trae la profecía de la Modernidad, la profecía que siempre estuvo subyacente al proyecto de racionalización: que toda decisión sea tomada con base en la inequívoca razón, que el poder y su compleja verticalidad estuviese marcado por la parsimonia del conocimiento, por la sabiduría de los expertos. La tecnocracia se ha erguido profeta, un desencantado profeta que cumple, pero no guía. La tecnocracia es el profeta de las soluciones a todo, pero es la ausencia de problemas últimos. Es la profecía de un mundo desencantado, la religión de una máquina. La limpia efícacia y el pacífico consenso de un saber unidimensional son sus cartas de presentación. Pero es un profeta sin carisma, una tradición sin historia, unos valores relativos, una razón del absurdo. La tecnocracia se ha erguido profeta para anunciar el mundo nuevo, salvífico, de la optimización y la certeza. Promete un impersonal reino de modelos de análisis y una nueva clase de científicos-sacerdotes a su cargo, convirtiendo la hermenéutica y exégesis del libro sagrado en la operatoria que conduce al nuevo sentido del mundo: la inequívoca optimización.

Pero la Modernidad no era esta promesa. Una razón operatoria es todo lo contrario de los ideales emancipatorios y del hombre como constructor de su historia. Una política desprovista de la dimensión de la decisión es la ausencia misma de politicidad. Una ciencia desprovista de debate, de riquezas paradigmáticas, es la ausencia de conocimiento. La profecía es falsa, como lo es el profeta. Si la tecnocracia se instala en el Estado habrá hallado su iglesia e instalará sus sacerdotes que cumplirán su obvio e histórico rol: justificar que el reino no se parece a la promesa. Quizás entonces sea demasiado tarde, quizás ya nadie pueda elegir el demonio que guía su vida y tendrá que aceptar el que le viene dado. Será una sutil jaula de fórmulas y números, la descarada jaula de la razón petrificada. 


\section{Bibliografía}

ADORNO, Theodor W; HORKHEIMER, Max (1977); Dialéctica de la Ilustración. México D. F.: Editorial Sudamericana.

ATRIA, Raúl (1999); "La Sociología Actual y el Espíritu de la Modernidad" en Revista de Sociología. Santiago: Departamento de Sociología de la Universidad de Chile, Número 13, 1999.

BARZELAY, Michael (2001); "La nueva gerencia pública. Un ensayo bibliográfico para estudiosos latinoamericanos" en Revista Reforma y Democracia. No. 19 (Feb. 2001). Caracas

BELL, Daniel (1964); El Fin de las Ideologías. Madrid: Editorial Tecnos.

Editorial. (1986); El Advenimiento de la Sociedad Postindustrial. Madrid: Alianza

CAMOU, Antonio; "Los Consejeros del Príncipe" en Revista Nueva Sociedad número 152, Edición de Noviembre-Diciembre de 1997, Caracas, Venezuela

COMTE, Auguste (2000); Discurso sobre el Espíritu Positivo. Madrid: Alianza Editorial.

CROZIER, Michel; HUNTINGTON, Samuel; WATANUKI, Joji (1975); The Crisis of Democracy. New York: New York University Press.

ENGELS, Federico (s/f a); "El papel del Trabajo en la Transformación del Mono en Hombre" en ENGELS, Federico y MARX, Carlos; Obras Escogidas. Moscú: Editorial Progreso.

ENGELS, Federico y MARX, Carlos (s/f a); "El Manifiesto Comunista" en ENGELS, Federico y MARX, Carlos; Obras Escogidas. Moscú: Editorial Progreso.

FALETTO, Enzo (1999); "De la Teoría de la Dependencia al Proyecto Neoliberal: el Caso Chileno" en Revista de Sociología. Santiago: Departamento de Sociología de la Universidad de Chile, Número 13, 1999.

FEYERABEND, Paul (1984); Adiós a la Razón. Madrid: Editorial Tecnos. (2000); Tratado Contra el Método. Madrid: Editorial Tecnos.

FERNÁNDEZ DE LA MORA, Gonzalo (1973); El Crepúsculo de las Ideologías. Bogotá: Ediciones Colombianas.

FOUCAULT, Michel (1996); La Arqueología del Saber. México D.F.: Siglo XXI Editores. 
(1999); Las Palabras y las Cosas. Madrid: Siglo XXI Editores.

FUKUYAMA, Francis (1992); El Fin de la Historia y el Último Hombre. Buenos Aires: Editorial Planeta.

GARCÍA DE LA HUERTA, Marcos (1990); Crítica de la Razón Tecnocrática. Santiago: Editorial Universitaria.

GARCIA PELAYO, Manuel (1974); Burocracia y Tecnocracia y Otros Escritos. Madrid: Alianza Universidad.

GIDDENS, Anthony (1994); "¿Razón sin Revolución?" en Habermas y la Modernidad. Madrid: Ediciones Cátedra.

Editorial. (1995); Política y Sociología en Max Weber. Madrid: Alianza Madrid: Editorial Alianza.

(1996); La Estructura de Clases en las Sociedades Avanzadas. (1998); El Capitalismo y la Moderna Teoría Social. Barcelona: Idea Books.

HABERMAS, Jürgen (1982); Conocimiento e Interés. Madrid: Editorial Taurus.

(1985); "La Modernidad, un Proyecto Incompleto" en FOSTER, Hal (edit); La Posmodernidad. Barcelona: editorial Kairós.

Tecnos.

(1989a); Ciencia y Técnica como Ideología. Madrid: Editorial (1989b); El Discurso Filosófico de la Modernidad. Madrid:

Editorial Taurus.

(1990); Teoría y Praxis. Madrid: Editorial Tecnos.

(1998); Facticidad y Validez. Madrid: Editorial Trotta.

(1999a); Teoría de la Acción Comunicativa, I: racionalidad de la acción y racionalización social. Madrid: Editorial Taurus.

(1999b); Teoría de la Acción Comunicativa, II: crítica de la razón funcionalista. Madrid: Editorial Taurus.

HORKHEIMER, Max (2000); Teoría Tradicional y Teoría Crítica. Barcelona: Paidós. 
KOSELlECK, Reinhart (1993); Futuro Pasado: para una Semántica de los tiempos históricos. Barcelona: Editorial Paidós.

KUHN, Thomas S. (1993); La Estructura de las Revoluciones Científicas. Santiago: Fondo de Cultura Económica.

LAHERA, Eugenio (1995); "Las Reformas del Estado" en Revista Chilena de Administración Pública. Año II, Agosto de 1995, Número 6.

LIPSET, Seymour Martin (1987); El Hombre Político: las bases sociales de la política. Madrid: Editorial Tecnos.

LYOTARD, Jean Francois (1995); La Condición Postmoderna. Buenos Aires: Editorial REI.

MARCUSE, Herbert (1968); El Hombre Unidimensional. Ensayos sobre la ideología de la sociedad industrial avanzada. México D.F.: Editorial Joaquín Mortiz.

MEYNAUD, Jean (1965); Problemas Ideológicos del Siglo XX:el destino de las ideologías y tecnocracia y política. Barcelona: Ediciones Ariel.

MEYNAUD, Jean (1968); La tecnocracia: ¿mito o realidad?. Madrid: Editorial Tecnos.

MONTECINOS, Verónica; "El Valor Simbólico de los Economistas en la Democratización de la Política Chilena" en Revista Nueva Sociedad Número 152, Edición de NoviembreDiciembre de 1997, Caracas, Venezuela.

PARSONS, Talcott (1971); "Evaluación y Objetividad en el Ámbito de las Ciencias Sociales: una interpretación de los trabajos de Max Weber" en Presencia de Max Weber. Buenos Aires: Ediciones Nueva Visión.

(1966); The Social System. Estados Unidos: free press paperback.

SERRANO, Enrique (1994); Legitimación y Racionalización. Weber y Habermas: la dimensión normativa de un orden secularizado. Barcelona: Editorial Anthropos.

SILVA, Patricio; "Ascenso Tecnocrático y Democracia en América Latina" en Revista Nueva Sociedad Número 152, Edición de Noviembre-Diciembre de 1997, Caracas, Venezuela.

SOLARI, Ricardo, TOHÁ, Carolina (1996); "La Modernización del estado y la Gerencia Pública". En http://www.fes.cl/pdf/1996moderniza.pdf

STERNBERGER, Dolf (1992); Dominación y Acuerdo. Barcelona: Gedisa editorial.

TOURAINE, Alain (1973); La Sociedad Postindustrial. Barcelona: Editorial Ariel. 
Económica.

(1994); Crítica de la Modernidad. Buenos Aires: Fondo de Cultura

VALLESPÍN, Fernando (1997); "Introducción" en LUHMANN, Niklas; Teoría Política en el Estado de Bienestar. Madrid: Editorial Alianza Universidad.

VARGAS, José (s/f); Las Relaciones de los Fundamentos Teóricos entre la 'Nuev aEconomía Política', la 'Nueva Gerencia Pública' y la 'Nueva Política Social'. Mímeo.

VON BEYME, Klaus (1994); Teoría Política del Siglo XXI: de la modernidad a la postmodernidad. Madrid: Alianza Editorial.

WALLERSTEIN, Immanuell (1999); Después del Liberalismo. México D. F.: Siglo XXI editores.

WEBER, Max (1993); El Político y el Científico. Madrid: Alianza Editorial.

(1996); Economía y Sociedad. México: Fondo de Cultura Económica.

(1998a); "La Ética Protestante y el Espíritu del Capitalismo" en Ensayos Sobre Sociología de la Religión, I. Madrid: Taurus.

(1998b); "La Ética Económica de las Religiones Universales" en Ensayos Sobre Sociología de la Religión, I. Madrid: Taurus.

WELLMER, Albrecht (1994); "¿Razón, Utopía y la Dialéctica de la Ilustración?" en Habermas y la Modernidad. Madrid: Ediciones Cátedra.

WRIGHT MILLS, C (1987); La Imaginación Sociológica. México D. F.: Fondo de Cultura Económica. 